
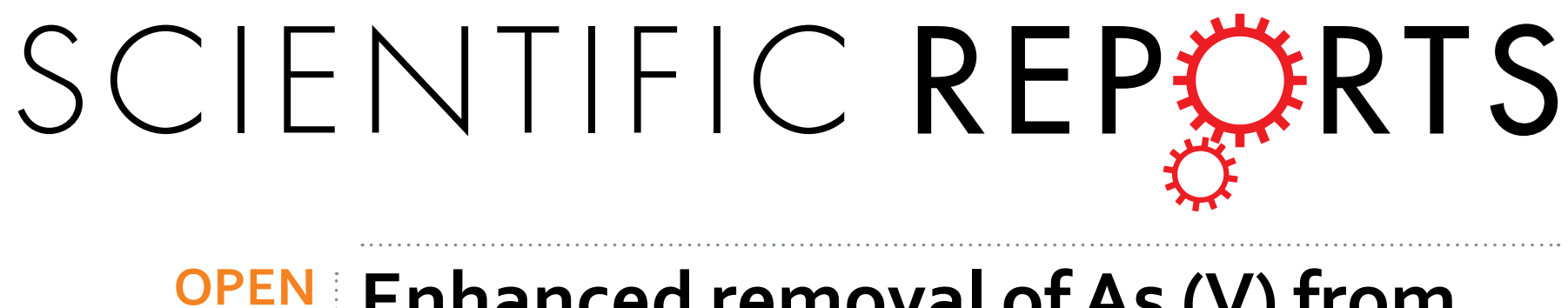

\title{
Enhanced removal of As (V) from aqueous solution using modified hydrous ferric oxide nanoparticles
}

Received: 28 June 2016

Accepted: 12 December 2016

Published: 18 January 2017
Lijuan Huo ${ }^{1,2}$, Xibai Zeng ${ }^{1}$, Shiming Su ${ }^{1}$, Lingyu Bai ${ }^{1}$ \& Yanan Wang ${ }^{1}$

Hydrous ferric oxide (HFO) is most effective with high treatment capacity on arsenate [As(V)] sorption although its transformation and aggregation nature need further improvement. Here, HFO nanoparticles with carboxymethyl cellulose (CMC) or starch as modifier was synthesized for the purpose of stability improvement and $\mathrm{As}(\mathrm{V})$ removal from water. Comparatively, $\mathrm{CMC}$ might be the optimum stabilizer for HFO nanoparticles because of more effective physical and chemical stability. The large-pore structure, high surface specific area, and the non-aggregated nature of CMC-HFO lead to increased adsorption sites, and thus high adsorption capacities of $\mathrm{As}(\mathrm{V})$ without pre-treatment (355 $\left.\mathrm{mg} \cdot \mathrm{g}^{-1}\right)$, which is much greater than those reported in previous studies. Second-order equation and dual-mode isotherm model could be successfully used to interpret the sorption kinetics and isotherms of $A s(V)$, respectively. FTIR, XPS and XRD analyses suggested that precipitation and surface complexation were primary mechanisms for $\mathrm{As}(\mathrm{V})$ removal by CMC modified HFO nanoparticles. A surface complexation model (SCM) was used to simulate As adsorption over pH 2.5-10.4. The predominant adsorbed arsenate species were modeled as bidentate binuclear surface complexes at low $\mathrm{pH}$ and as monodentate complexes at high $\mathrm{pH}$. The immobilized arsenic remained stable when aging for $270 \mathrm{~d}$ at room temperature.

Arsenic (As) is a priority pollutant because of its highly toxicity and potential effects on public health and environmental safety worldwide. It has been detected widely in groundwater and soil and is particularly associated with waste from mining, petroleum refining, and ceramics manufacturing; agricultural chemicals; sewage sludge; and coal fly ash ${ }^{1}$. The efficiency of As cleanup by artificial adsorbents, such as iron (Fe) oxides (e.g., magnetite, ferrihydrite, goethite, and zero-valent iron $[\mathrm{ZVI}])^{2-7}$, activated alumina ${ }^{8,9}$, polymeric ligand exchangers ${ }^{10}$, red mud $^{11}$, and activated carbon ${ }^{12,13}$, titanium oxide, has been extensively investigated in recent years. Fe(III) has high affinity for inorganic As species and selectively performs As sorption ${ }^{1,12}$. Inner sphere surface complexation can explain the strong interactions between $\mathrm{As}(\mathrm{V})$ and various $\mathrm{Fe}$ oxides ${ }^{14,15}$. Especially hydrous ferric oxide (HFO) is most effective for removing both $\mathrm{As}(\mathrm{III})$ and $\mathrm{As}(\mathrm{V})$ from aqueous solution because of its high specific surface area and iso-electric point ${ }^{10}$. However, the poorly crystalline HFO transforms into more crystalline iron forms, such as hematite or goethite, over time ${ }^{16}$, greatly diminishing its high reactivity with As and efficiency in its removal. Moreover, diffusion limitations within micrometer-sized HFO particles decrease their adsorption rate and available capacity ${ }^{17}$.

Recently, nanoadsorbents have made strong momentum in water and soil remediation engineering ${ }^{18-20}$. Nanoscale Fe oxide particles have larger specific surface area and potentially higher reactivity than bulk particles or natural minerals, which should confer greater sorption capacity. However, nanoparticles can undergo irreversible aggregation, which may reduce their sorption capacity and hinder their effectiveness ${ }^{21}$. Therefore, Fe oxides particles were decorated with various functional groups to enhance their dispersibility and performance ${ }^{7,17,22-27}$. Another unique advantage of well dispersed nanoparticles is that they can be directly delivered into contaminated soil or groundwater to facilitate in situ removal of target contaminants ${ }^{28}$. However, the modifier coatings for the HFO should play a maximum effectiveness for $\mathrm{As}(\mathrm{V})$ immobilization, while the negative ecological consequences also need to be considered.

${ }^{1}$ Institute of Environment and Sustainable Development in Agriculture, Chinese Academy of Agricultural Sciences, Beijing, 100081, China. ${ }^{2}$ College of Environment and Safety, Taiyuan University of Science and Technology, Taiyuan, Shanxi, 030024, China. Correspondence and requests for materials should be addressed to X.Z. (email: zengxibai@ caas.cn) 

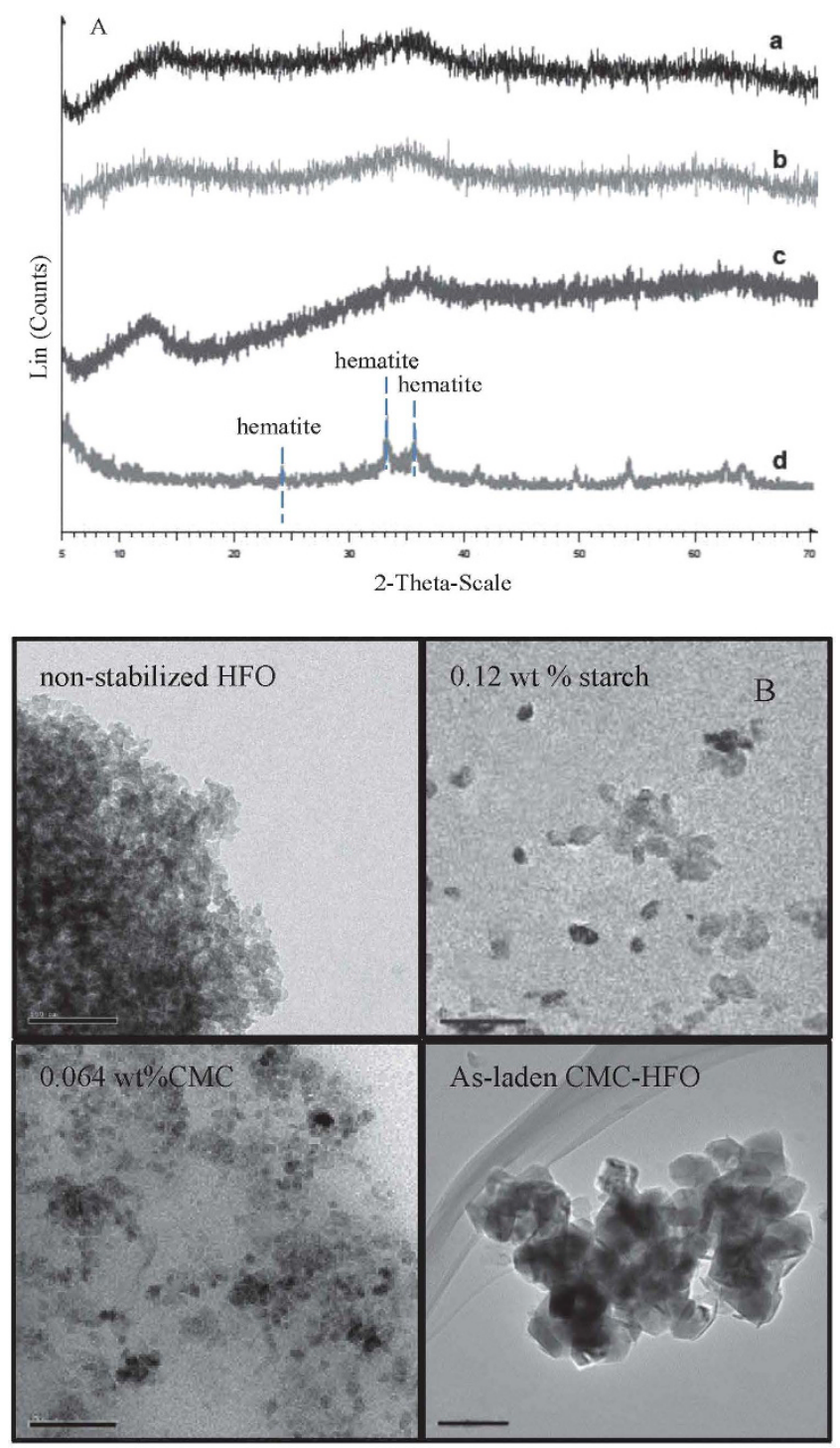

Figure 1. TEM image (B) and XRD spectra (A) of modified HFO nanoparticles: (a) 1 day and (b) 15days after HFO nanoparticles preparation with CMC stabilized (c) 1 day (d) 15 days after HFO particles preparation without modifier. The scale bar represents $100 \mathrm{~nm}$.

Starch and carboxymethyl cellulose (CMC) are both low-cost and environmentally friendly, and they share similar macromolecular skeletons. Importantly, CMC carries carboxylate and hydroxyl groups ${ }^{19}$. They have been used as stabilizer materials in preparing ZVI, FeS, Fe-Mn oxides, or magnetite nanoparticles for heavy metals and organic contaminants ${ }^{21,22,29-31}$. It was reported the primary mechanism for binding $\mathrm{CMC}$ to $\mathrm{Fe}^{2+}$ was bidentate bridging while starch worked through steric stabilization ${ }^{19}$. Comparatively, $\mathrm{Fe}^{3+}$ is easier to complex with oxygen groups than $\mathrm{Fe}^{2+32}$. However, the understanding remains lacking on the binding mechanisms of $\mathrm{Fe}^{3+}$ and $\mathrm{CMC}$ or starch, as well as their performance in $\mathrm{As}(\mathrm{V})$ removal from aqueous solution.

In this work, in order to examine the effective removal of arsenate $[\mathrm{As}(\mathrm{V})]$ from aqueous solution, a series of HFO nanoparticles modified with various concentrations of starch or CMC were synthesized. The objectives were to (I) characterize the modified HFO nanoparticles and elucidate the stability mechanism; (II) test the effects of type and concentration of modifier, reaction time and solution $\mathrm{pH}$ on the effectiveness of As(V) sorption; (III) elucidate the As sorption kinetics, isotherm, and mechanism; (IV) test the effects of nanoparticle aging on As(V) immobilization and long-term stability; and (V) examine the reusability of the regenerated modified HFO nanoparticles for subsequent cycles of $\mathrm{As}(\mathrm{V})$ sorption.

\section{Results and Discussion}

Characterization of the modified HFO nanoparticles. The physical properties of the modified HFO particles, including their morphology, mean size, chemical and physical stability were measured by TEM, XRD, XPS, DLS and UV-vis analysis. The TEM micrographs of HFO particles prepared without a modifier, with $0.064 \mathrm{wt} \% \mathrm{CMC}$, and with $0.12 \mathrm{wt} \%$ starch were shown in Fig. 1. Bare HFO particles aggregated and precipitated 

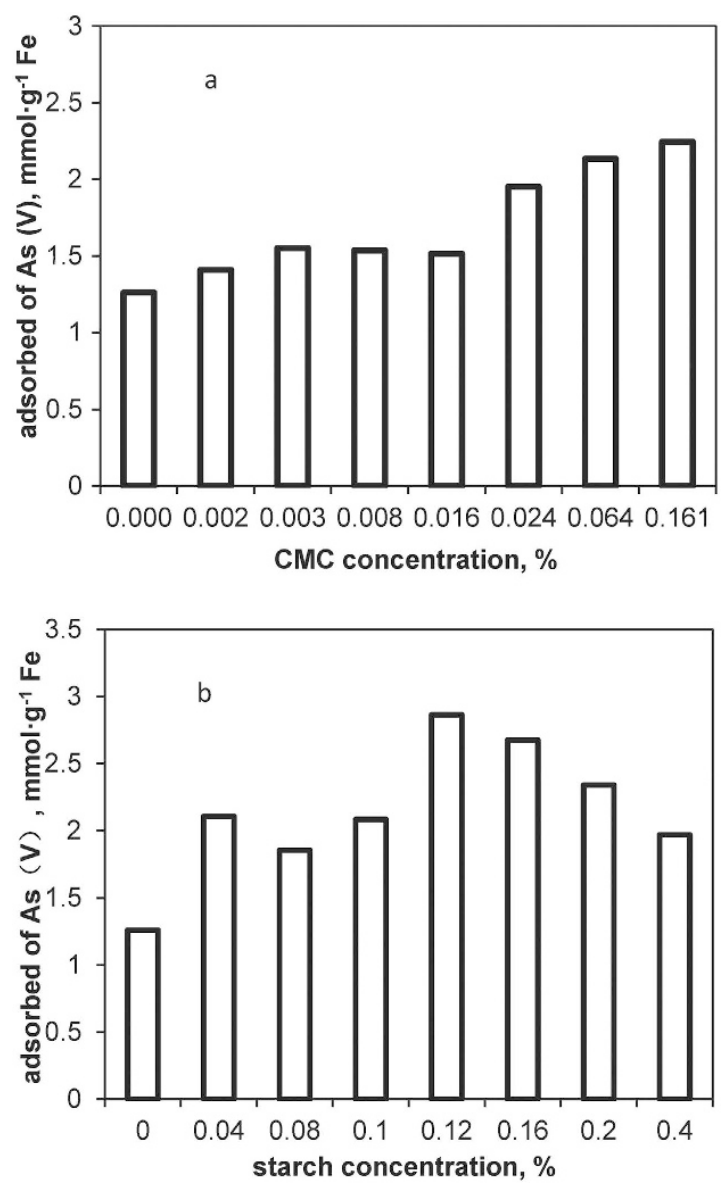

Figure 2. Effect of CMC (a) or starch (b) concentration on As (V) adsorption (q, mmol.g $\left.\mathbf{g}^{-1} \mathrm{Fe}\right)$. Nanoparticle dosage $=100 \mathrm{mg} \cdot \mathrm{L}^{-1}$ as $\mathrm{Fe}$, initial As $(\mathrm{V})$ concentration $=30 \mathrm{mg} \cdot \mathrm{L}^{-1}$, equilibrium $\mathrm{pH}=7.0$, equilibrium time $=72 \mathrm{~h}$.

quickly, appearing as large floccules (Figure S1 in Supplemental Information (SI)), while CMC or starch-modified HFO nanoparticles remained clearly discrete and well-dispersed in water (0.064 wt\% CMC and $0.12 \mathrm{wt} \% \mathrm{starch})$. The mean size of the freshly prepared, CMC-stabilized nanoparticles was $\sim 12 \mathrm{~nm}$ dispersed in CMC solution (Fig. 1B). DLS tests were also conducted on the modified HFO nanoparticles to obtain the dynamic"wet"particle size distribution. After $24 \mathrm{~h}$ of standing, the average hydrodynamic diameters of the bare HFO particles and those modified with $0.064 \%$ CMC and $0.12 \%$ starch were 1605,216 , and $283 \mathrm{~nm}$, respectively. Figure S2 of SI displays the hydrodynamic size distributions of the particles at various CMC concentrations. At a CMC concentration of $0.064 \mathrm{wt} \%$, fully stabilized HFO nanoparticles were obtained with a relatively narrow size distribution $(>70 \%$ of the particles fall between 100 and $150 \mathrm{~nm}$ ). At lower concentrations, the stabilizer serves conducts as a flocculating or bridging agent, to promote flocculation of particles flocculation or destabilization. When CMC or starch concentration exceeds a fixed value, the coating serves as a stabilizer, facilitating effective particle stabilization ${ }^{30}$. Yet, during a 180 days sediment test, the stabilized nanoparticles remained fully suspended. DLS revealed particle diameters of 227 and $378 \mathrm{~nm}$ for the CMC- and starch-modified particles, respectively. The measured $\zeta$ potential values of the HFO suspensions at $\mathrm{pH} 7.0$ were $20.9,1.3$, and $-38.9 \mathrm{mV}$ for non-modified, starch-stabilized, and CMC-stabilized modified particles, respectively. Figure 1A also shows the XRD diffractograms of the prepared HFO nanoparticles in the presence and absence of stabilizer after prepared for $15 \mathrm{~d}$. Hydrous Fe (III) oxides could convert to the crystalline Fe (III) oxides gradually ${ }^{33}$, but this did not happen for the CMC-modified nanoparticles. In the composites, no additional diffraction peaks appeared, suggesting that the particles are amorphous. However, the bare HFO nanoparticles contained a very small amount of crystalline hematite, which exhibit three weak peaks associated with the crystal structure of hematite at $24.06^{\circ}, 33.14^{\circ}$, and $35.62^{\circ}$ (Fig. $1 \mathrm{~d}$ ). UV-vis absorbance result (Figure S3) also illustrates the effects of CMC concentration on the HFO nanoparticles' physical stability, and is described in S1 of SI. No significant changes in XRD spectra were found for the CMC-HFO nanoparticles, indicating that they are quite stable physically and chemically.

Effects of modifier concentration on HFO nanoparticle stability and arsenic removal. Batch sorption tests were conducted to obtain the sorption capacity of $\mathrm{As}(\mathrm{V})$ on different modified HFO particles. Figure 2 shows the effect of stabilizer concentration on equilibrium uptake of As(V) by HFO nanoparticles. In general, As $(\mathrm{V})$ uptake increased with elevated $\mathrm{CMC}$ and starch concentration in the ranges of $0-0.161 \mathrm{wt} \%$ and $0-0.4$ wt \%, respectively (Fig. 2). The modified composites gave much greater As(V) uptake than did bare HFO. 


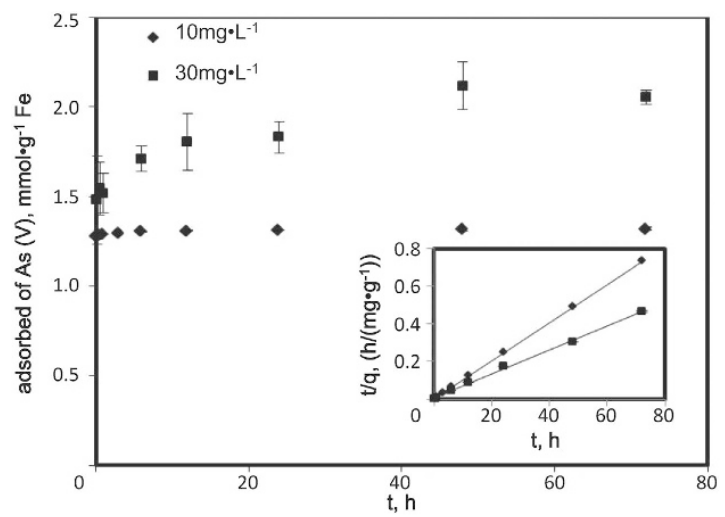

Figure 3. Uptake of As(V) by CMC-HFO nanoparticles. Initial $\mathrm{As}(\mathrm{V})=10$ and $30 \mathrm{mg} \cdot \mathrm{L}^{-1}$, $\mathrm{HFO}$ particles as $\mathrm{Fe}=100 \mathrm{mg} \cdot \mathrm{L}^{-1}, \mathrm{CMC}=0.064 \%(\mathrm{w} / \mathrm{w})$, initial $\mathrm{pH}\left(\mathrm{pH}_{0}\right)=6.5$, and final $\mathrm{pH}\left(\mathrm{pH}_{\mathrm{f}}\right)=7.0$. Control tests were performed with no HFO $(0.064 \mathrm{wt} \% \mathrm{CMC})$. Inset is the plot of $\mathrm{t} / \mathrm{q}_{\mathrm{t}}$ versus $\mathrm{t}$ using linear regression fitting a pseudo-second-order model.

The fully stabilized HFO nanoparticles ( $0.12 \mathrm{wt} \%$ starch and $0.064 \mathrm{wt} \% \mathrm{CMC}$ ) offered 2.31 and 1.69 times greater $\mathrm{As}(\mathrm{V})$ uptake than nonstabilized particles, respectively. This could be explained by the smaller size and the greater specific surface area of the modified nanoparticles. Larger CMC concentrations resulted in smaller size particles (Figure S2). Yean et al. ${ }^{34}$ and Auffan et al. ${ }^{35}$ reported that smaller-sized materials greatly improved As(V) adsorption capacity. As the particle size was reduced from 300 to $11 \mathrm{~nm}$, the amount of adsorbed $\mathrm{As}(\mathrm{V})$ increased from 0.02 to $1.8 \mathrm{mmol} \cdot \mathrm{g}^{-1}$ of magnetite $\left(\mathrm{Fe}_{3} \mathrm{O}_{4}\right)^{34}$. Liang et al. ${ }^{31}$ observed that the sorption capacity was increased from 26 to $63 \mathrm{mg} / \mathrm{g}$ when the magnetite nanoparticle size ranged from $\sim 200-75 \mathrm{~nm}$. Nevertheless, As(V) uptake was inhibited when the starch concentration increased from 0.12 to $0.4 \mathrm{wt} \%$ (Fig. 2b). While the sorption capacity increased by $5 \%$ when CMC concentration increased from 0.064 to $0.161 \mathrm{wt} \%$ (Fig. 2a). Excessive uptake of CMC or starch molecules resulted in a denser coating on the nanoparticles' surface, which was also used for zero iron, $\mathrm{FeS}$ and Fe-Pd nanoparticles preparation ${ }^{21,29,30}$. The associated elevated mass transfer resistance or sorption site blockage can inhibit As(V)'s access both kinetically and thermodynamically ${ }^{30}$.

Among the fully stabilized nanoparticles, those with $0.12 \mathrm{wt} \%$ starch offered 1.34 times greater As(V) removal than CMC stabilization, while CMC stabilization is associated with smaller particles. At the experimental $\mathrm{pH}$ of 7.0, $\mathrm{H}_{2} \mathrm{AsO}_{4}{ }^{-}$and $\mathrm{HAsO}_{4}{ }^{2-}$ are the dominant arsenate species ${ }^{36}$. As CMC-modified $\mathrm{HFO}$ nanoparticles have a highly negatively charged surface $(\zeta$ potential $-38.9 \mathrm{mV})$, the anions would need to overcome the energy barrier created by electrostatic repulsion in order to undergo sorption. Although starches can stabilize HFO nanoparticles in aqueous solutions, their effectiveness is limited by weaker, interfacial bonding with the particle surface and their lower-magnitude $\zeta$ potentials than CMC. In contrast, CMC consists of oxygen-containing functional groups (e.g., $-\mathrm{COOH},-\mathrm{OH}$, and $-\mathrm{CO}$ ) and stabilizing, hydrocarbon chains, which can interact with particles much more strongly than starch. CMC thus serves as a more effective capping agent ${ }^{37}$. The anchoring groups can attach chemically or physically onto the HFO nanoparticle surface, while the stabilizing chains can freely rotate and take on varied configurations in water ${ }^{38}$. He et al. ${ }^{39}$ concluded that $\mathrm{CMC}$ molecules complex with $\mathrm{Fe}^{2+}$ to give the precursor CMC- $\mathrm{Fe}^{2+}$ in the synthesis of nanoparticles. The complexation did not appear to hinder significantly the subsequent reduction or co-precipitation of the $\mathrm{Fe}^{2+}$ possibly owing to the rather bulky and loose structure of the CMC molecules. Thus, the primary role of CMC lies in facilitating the subsequent nucleation and growth of the composites, thereby prevent the aggregation of nanoparticles via electrosteric stabilization ${ }^{19}$. Moreover, as described above, CMC requires a lower concentration than starch to achieve full stabilization of HFO nanoparticles (0.064 and $0.16 \mathrm{wt} \%$ for CMC and starch, respectively). When all factors, including As(V) sorption, physical stability, and environmental effects, are analyzed together, it could be easily inferred that CMC might be the optimum stabilizer for HFO nanoparticles. The optimal concentration of CMC was determined to be $0.064 \mathrm{wt} \%$.

Arsenic sorption kinetics and isotherm. The effect of As(V) sorption kinetics and isotherm on CMC modified HFO nanoparticles were evaluated. Figure 3 shows the results of kinetics tests on CMC-modified HFO nanoparticles with $\mathrm{Fe}$ at $100 \mathrm{mg} \cdot \mathrm{L}^{-1}$ and $\mathrm{As}(\mathrm{V})$ at an initial concentration of 10 and $30 \mathrm{mg} \cdot \mathrm{L}^{-1}$. Overall, the sorption rate is characterized with a rapid initial rate $($ at $<1 \mathrm{~h})$ followed by a rather slower phase until reaching equilibrium at $72 \mathrm{~h}$. At equilibrium, $99 \%$ of the $\mathrm{As}(\mathrm{V})$ had been removed from the aqueous when the initial $\mathrm{As}(\mathrm{V})$ concentration was $10 \mathrm{mg} \cdot \mathrm{L}^{-1}$. The first-order, second-order and intraparticle diffusion models were used to simulate the kinetics data; Fig. 3 also provides best fitting curves to these models. The second-order kinetics was able to adequately interpret the batch kinetic data $\left(\mathrm{R}^{2}=0.997\right.$ and 1$)$. It was consistent with the findings by Zhu et al. ${ }^{40}$ and Goh et al ${ }^{41}$, who modeled As(V) sorption kinetics by hydrous ferric oxide and $\mathrm{Mg} / \mathrm{Al}$ layered double hydroxide. The results indicated that the rate-limiting step is sorption rather than diffusion.

Figure 4 shows the $\mathrm{As}(\mathrm{V})$ sorption isotherm for the modified HFO nanoparticles at $\mathrm{pH}$ 7.0. The experimental data were fit to the classical Langmuir and Freundlich models. The Langmuir model outperformed the Freundlich model $\left(\mathrm{R}^{2}=0.9873\right.$ and 0.9086 , respectively), consistent with findings by An et al. ${ }^{42}$. For mechanistic soundness, a dual-mode isotherm model that incorporates both precipitation and adsorption (i.e., ion exchange and surface complexation) was applied to simulate the experimental data ${ }^{30}$ : 


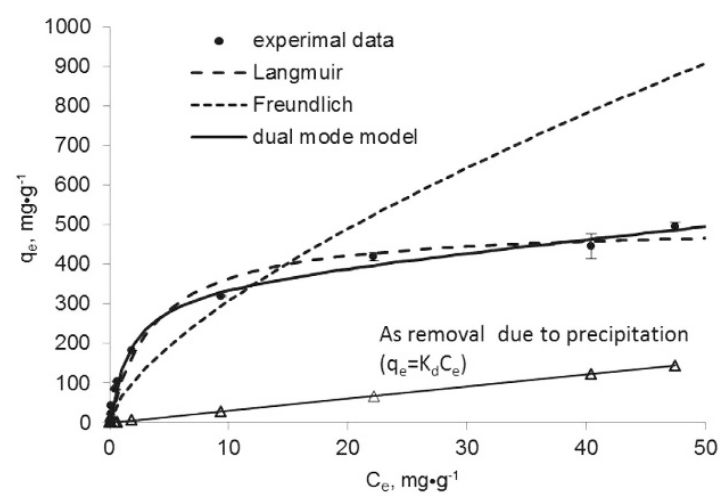

Figure 4. Arsenic sorption isotherm of CMC- HFO nanoparticles. $\mathrm{HFO}$ particles as $\mathrm{Fe}=100 \mathrm{mg} \cdot \mathrm{L}^{-1}$, initial $\mathrm{As}(\mathrm{V})$ concentration $=0.1-100 \mathrm{mg} \cdot \mathrm{L}^{-1}$, initial $\mathrm{pH}=7.0$. Symbols: experimental data; lines: model fittings.

$$
q_{e}=K_{d} C_{e}+\frac{b Q C_{e}}{1+b C_{e}},
$$

where $q_{e}, C_{e}, K_{d}, b$, and $Q$ represent total As $(\mathrm{V})$ uptake $\left(\mathrm{mg} \cdot \mathrm{g}^{-1}\right)$, equilibrium concentration of $\mathrm{As}(\mathrm{V})$ in solution $\left(\mathrm{mg} \cdot \mathrm{L}^{-1}\right)$, the linear distribution coefficient $\left(\mathrm{L} \cdot \mathrm{mg}^{-1}\right)$ associated with precipitation, the Langmuir affinity constant $\left(\mathrm{L} \cdot \mathrm{mg}^{-1}\right)$, and the Langmuir maximum sorption capacity $\left(\mathrm{mg} \cdot \mathrm{g}^{-1}\right)$, respectively. In theory, the first and second terms represent $\mathrm{As}(\mathrm{V})$ precipitation (which is considered to be linearly related to $C_{e}$ ) and adsorption, respectively. The nonlinear fitting verifies that the dual-mode model best parameterizes the experimental data, providing the best fit $\left(\mathrm{R}^{2}=0.9966\right)$ and the adsorption capacity $355.3 \mathrm{mg} \cdot \mathrm{g}^{-1}$ as Fe. The same formula has been successfully used to model sorption of mercury onto FeS nanoparticles ${ }^{30}$. Figure 4 also illustrates precipitation becomes more important following the increased As concentrations. At lower concentration of $\mathrm{As}(\mathrm{V})\left(\mathrm{Ce}<9.39 \mathrm{mg} \cdot \mathrm{L}^{-1}\right.$, initial As/Fe $<0.4)$, more than $97 \%$ of the observed $\mathrm{As}(\mathrm{V})$ removal was attributed to adsorption. Increased As(V) loading saturated the HFO nanoparticles' adsorption capacity, giving rise to precipitation: at Ce $>40 \mathrm{mg} \cdot \mathrm{L}^{-1}$ (initial As/ $\mathrm{Fe}>0.6), 15 \%-28 \%$ of $\mathrm{As}(\mathrm{V})$ removal was due to precipitation. Similar findings were reported by Tokoro et al. ${ }^{6}$, who studied $\mathrm{As}(\mathrm{V})$ coprecipitation with $\mathrm{HFO}$ at $\mathrm{pH} 5$ and 7 . They concluded that at $\mathrm{As} / \mathrm{Fe}<0.4$, adsorption mainly caused $\mathrm{As}(\mathrm{V})$ removal, whereas at $\mathrm{As} / \mathrm{Fe}>0.4$, ferric arsenate formed a surface complex.

Table 1 compares the Q-values of the present systems' by some reported procedures. Decorating HFO with CMC performs significantly improved adsorption capacity for $\mathrm{As}(\mathrm{V})$ compared with those of previously reported. The maximum adsorption capacity enhanced at least 1.43 times than the values reported in previous studies as we know. Furthermore, this feature of CMC modified HFO nanoparticle developed in this work was synthesized through direct synthesis at normal experiments, which is much more convenient and cost-effective for large scale operations. Taking As $(\mathrm{V})$ sorption capacity and the preparation costs into account, the CMC-HFO nanoparticle is a rather promising alternative for $\mathrm{As}(\mathrm{V})$ removal. However, the CMC-to-HFO ratio will need to be adjusted such that the resulting CMC-HFO nanoparticles, referred to as flocculated nanoparticles, can have the advantage of the high specific surface area and easy separation by gravity-settling.

Arsenic sorption mechanism of CMC modified nanoparticles. FTIR spectroscopy was used to elucidate the mixtures' stabilization mechanisms and clarify the properties of the chemical bonding between HFO, $\mathrm{CMC}$, and As(V). Figure 5 presents the FTIR spectra of neat CMC, bare HFO, and modified HFO before and after As(V) sorption. The spectrum for bare HFO particles showed a peak at $1660 \mathrm{~cm}^{-1}$ and another at $3469 \mathrm{~cm}^{-1}$ (Fig. 5a), corresponding to the $\mathrm{O}-\mathrm{H}$ bond from $\mathrm{H}_{2} \mathrm{O}^{48}$. It is reported that the $\mathrm{pK}_{\mathrm{a}}$ value of CMC is $4.3^{4}$, and in all synthesis procedures, the $\mathrm{pH}$ was above 5.3. Therefore, the carboxylic acid groups and hydroxyl of CMC are expected to be almost fully disassociated. The carboxylic acid and hydroxyl groups interact strongly with the $\mathrm{Fe}^{3+}$ cations. Three FTIR peaks were observed for CMC-HFO nanoparticles at wavenumbers 1465, 1633 and $3423 \mathrm{~cm}^{-1}$ because of interactions between $\mathrm{COO}^{-}\left(1465\right.$ and $\left.1633 \mathrm{~cm}^{-1}\right)$ or $-\mathrm{OH}\left(3423 \mathrm{~cm}^{-1}\right)$ and Fe (Fig. $5 \mathrm{c}$ ). The stretching frequencies for the functional groups of CMC are expected to shift significantly if CMC molecules are adsorbed to the surface of the Fe nanoparticles ${ }^{49}$; thus, it is worth noting that the $-\mathrm{OH}$ stretching band shifts from $3450 \mathrm{~cm}^{-1}$ to $3423 \mathrm{~cm}^{-1}$ for CMC and CMC-HFO particles, respectively. This observation demonstrates that an enhanced intermolecular hydrogen bond is formed between $\mathrm{CMC}$ and the $\mathrm{Fe}^{3+19}$. The peaks at 1620 and $1433 \mathrm{~cm}^{-1}$ for $\mathrm{CMC}$ are assigned to asymmetric and symmetric $\mathrm{COO}^{-}$groups, respectively; these peaks were shifted to 1633 and $1325 \mathrm{~cm}^{-1}$, respectively, for CMC-HFO (Fig. 5c). The difference between the asymmetric and symmetric stretches $[\Delta v=\Delta($ asym $)-\Delta($ sym $)]$ of the carboxylate group was $308 \mathrm{~cm}^{-119,30}$, suggesting that $\mathrm{CMC}-\mathrm{Fe}^{3+}$ binding is governed by monodentate bridging. In addition, compared with that of CMC, the bond strength of the -OH group increased for CMC-HFO. This increase indicated the existence of an enhanced intermolecular hydrogen bond between $\mathrm{CMC}$ and Fe. An et al. ${ }^{42}$ reported that the peaks associated with the $\mathrm{H}$-bonded $-\mathrm{OH}$ groups of $\mathrm{CMC}$ were greatly intensified for CMC-bearing magnetite nanoparticles, which was consistent with our FTIR results. 


\begin{tabular}{|c|c|c|}
\hline Sorbent & $\operatorname{As}(\mathrm{V}) \mathbf{Q}_{\max }(\mathrm{mg} / \mathrm{g})$ & Ref. \\
\hline HFO coated activated carbon $(7.5 \% \mathrm{Fe})$ & 260 & $(\text { Jang })^{1}$ \\
\hline ultrafine $\alpha-\mathrm{Fe}_{2} \mathrm{O}_{3}$ nanoparticles & 47 & $(\text { Tang })^{4}$ \\
\hline$\gamma$-alumina nanocrystalline $(0.25 \mathrm{~g})$ & 27.75 & $(\mathrm{Li})^{8}$ \\
\hline polymeric ligand exchanger $(0.15 \mathrm{~g})$ & 92 & $(\mathrm{An})^{10}$ \\
\hline amorphous iron oxide & 157.33 & $(\text { Dixit })^{16}$ \\
\hline zero iron encapsulated chitosan nanospheres $\left(0.5 \mathrm{~g} \cdot \mathrm{L}^{-1}\right)$ & 119 & $(\text { Gupta })^{17}$ \\
\hline ionically modified magnetic nanomaterials $(120 \mathrm{mg})$ & 50.5 & (Badruddoza) $^{26}$ \\
\hline magnetite nanoparticles with starch $\left(0.1 \mathrm{~g} \cdot \mathrm{L}^{-1} \mathrm{Fe}\right)$ & 62 & $(\text { Liang })^{31}$ \\
\hline HFO Flocs & 139 & $(\text { Raven })^{33}$ \\
\hline magnetite nanoparticles with $\mathrm{CMC}\left(0.57 \mathrm{~g} \cdot \mathrm{L}^{-1} \mathrm{Fe}\right)$ & 248 & $(\mathrm{An})^{42}$ \\
\hline magnetite nanocrystals $\left(0.1 \mathrm{~g} \cdot \mathrm{L}^{-1} \mathrm{Fe}\right)$ & 241 & $(\text { Yean })^{34}$ \\
\hline$\gamma-\mathrm{Fe}_{2} \mathrm{O}_{3}$ Nanoparticles @ macroporous silica & 248 & $(\text { Yang })^{43}$ \\
\hline $\mathrm{Mg} / \mathrm{Al}$ Layered Double Hydroxide $\left(0.4 \mathrm{~g} \cdot \mathrm{L}^{-1}\right)$ & 85 & $(\mathrm{Goh})^{41}$ \\
\hline functionalized graphene sheets based electrodes & 142 & $(\text { Mishra })^{44}$ \\
\hline ß-FeOOH@GO-COOH composite (1 mg) & 45.7 & $(\text { Chen })^{45}$ \\
\hline iron oxide-graphene nanocomposite ( $5 \mathrm{mg}$ ) & 172.1 & $(\text { Mishra })^{46}$ \\
\hline $\mathrm{Fe}(\mathrm{III})$ loaded chelating resins $(0.2 \mathrm{~g})$ & 55.5 & $(\text { Matsunaga })^{47}$ \\
\hline HFO-CMC nanoparticle $\left(0.1 \mathrm{~g} \cdot \mathrm{L}^{-1} \mathrm{Fe}\right)$ & 355 & This work \\
\hline
\end{tabular}

Table 1. Comparison of As(V) adsorption capacity.

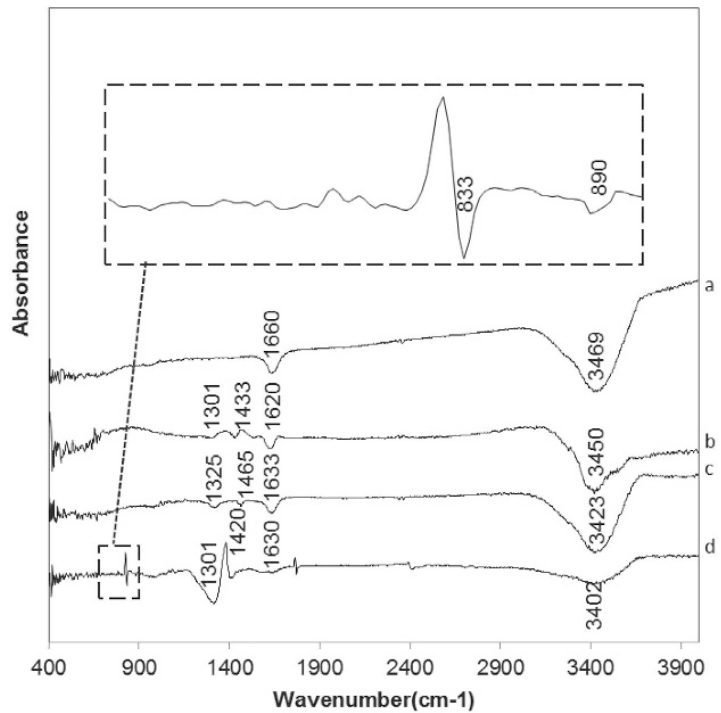

Figure 5. FT-IR spectra of (a) HFO (b) neat CMC (c) CMC-HFO nanoparticles (d) As laden CMC-HFO nanoparticles.

Comparing the spectrum of the CMC-HFO before and after As(V) sorption, new broad bands were evident at $\sim 833$ and $\sim 890 \mathrm{~cm}^{-1}$ for the As-laden HFO nanoparticles (Fig. 5d). The band at $\sim 833 \mathrm{~cm}^{-1}$ was due to coordination of the stretching As-O vibration with the Fe atom, i.e., As-O-Fe. Jia et al. ${ }^{50}$ conducted an FTIR study on sorption of $\mathrm{As}(\mathrm{V})$ to ferrihydrite and reported that poorly crystalline ferric arsenate shows a strong, well-resolved band at $\sim 838 \mathrm{~cm}^{-1}$, which was assigned to $\mathrm{Fe}-\mathrm{O}-\mathrm{As}$. They concluded that within the crystalline ferric arsenate structure, $\mathrm{AsO}_{4}$ tetrahedra and $\mathrm{FeO}_{4}\left(\mathrm{OH}_{2}\right)_{2}$ octahedra connected at alternate vertices; the band at $\sim 890 \mathrm{~cm}^{-1}$ (Fig. 5d) was assigned to uncomplexed/unprotonated As-O. For arsenate sorbed on amorphous Fe oxide, Goldberg and Johnston ${ }^{51}$ reported the existence of two distinct bands corresponding to surface-complexed and non-surface-complexed As-O groups. Moreover, the FTIR spectra showed similar absorption band characteristics to those found in the present study, such as those for the - $\mathrm{OH}$ group as well as the asymmetric and symmetric stretches of $\mathrm{COO}^{-}$groups $\left(3402,1630\right.$, and $1301 \mathrm{~cm}^{-1}$, respectively). However, the $-\mathrm{OH}$ stretching band shifted from $3423 \mathrm{~cm}^{-1}$ to $3402 \mathrm{~cm}^{-1}$ for CMC-HFO nanoparticles and As-laden CMC-HFO, respectively, while the frequency of the interaction between - $\mathrm{OH}$ and $\mathrm{Fe}$ commensurately decreased. The results showed a weakened $\mathrm{Fe}-\mathrm{OH}$ peak when As (V) was adsorbed onto the CMC-HFO nanoparticles; yet, the frequency of the symmetric stretch of the $\mathrm{COO}^{-}$group increased from 1325 to $1301 \mathrm{~cm}^{-1}$ for bare and As-laden CMC-HFO, respectively. 


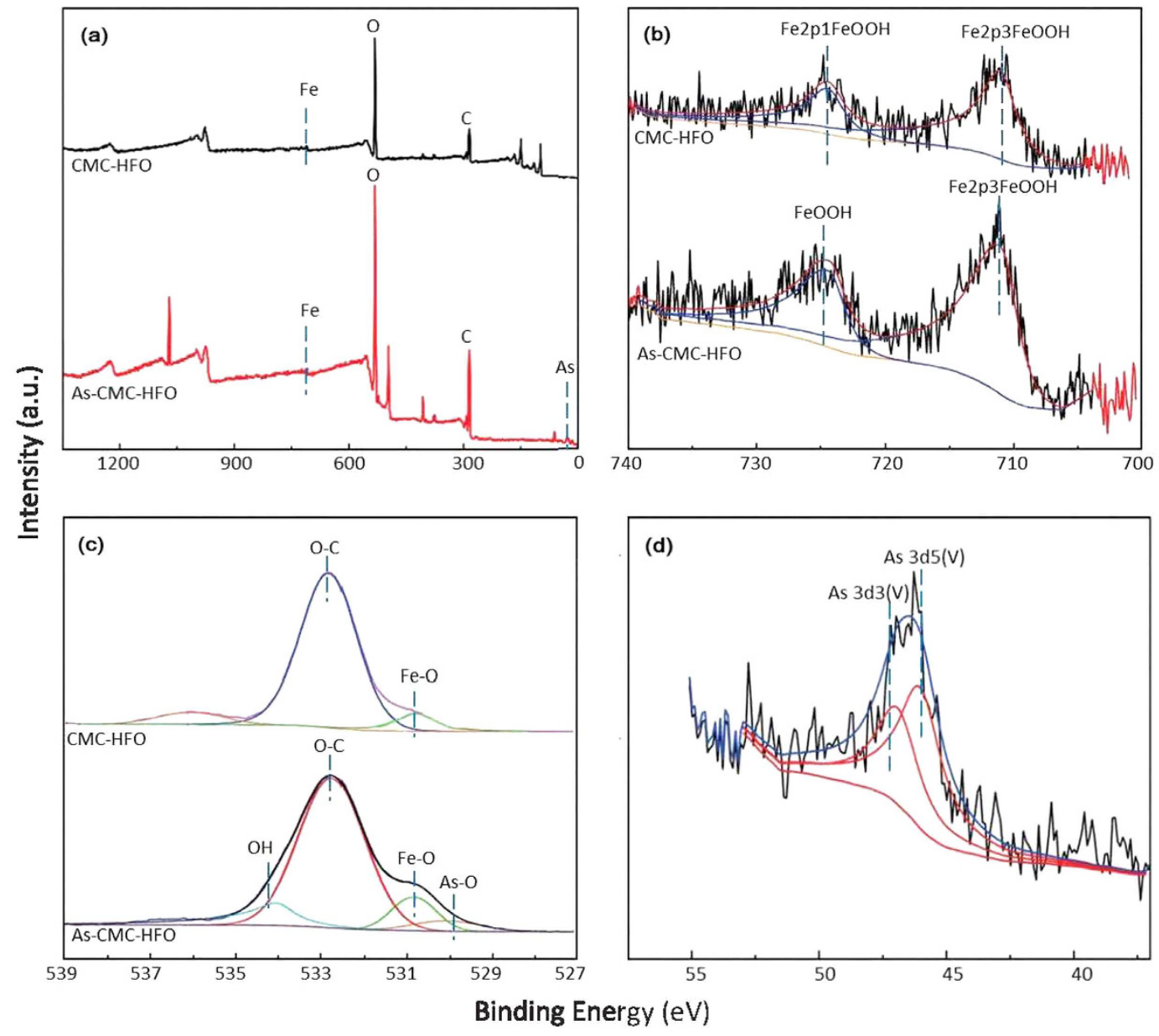

Figure 6. XPS survey scan (a) and corresponding high resolution spectra of Fe 2p (b) O1s (c) and As 3d (d) for fresh and As(V)-loaded CMC-HFO.

These changes were attributed to the complexation of As onto the $\mathrm{COO}^{-}$group of $\mathrm{CMC}$ because the abundance of $-\mathrm{OH}$ and $\mathrm{COO}^{-}$groups in $\mathrm{CMC}$ increased the number of available adsorption sites for $\mathrm{As}(\mathrm{V})$.

Figure S4 in SI presents XRD spectra of CMC-HFO particles mixed with As(V) and aged $30 \mathrm{~d}$ and $270 \mathrm{~d}$; they show a broad band at $\sim 34^{\circ} 2 \theta$. After $30 \mathrm{~d}$ of aging, a peak also appeared at $2 \theta$ values of $\sim 13^{\circ}$, corresponding to the characteristic peak of symplesite, but no other peaks were found in the 30 -day spectrum. After $270 \mathrm{~d}$ of aging at an initial pH of 7.0 at $25^{\circ} \mathrm{C}$, a weak band emerges at $\sim 28^{\circ} 2 \theta$, indicating the development of the ferric arsenate phase. The intensity of the band at $\sim 13^{\circ}$ was enhanced after $270 \mathrm{~d}$ of aging. Jia et al..$^{52}$ indicated that poorly crystalline ferric arsenate shows two broad XRD bands located at $\sim 28^{\circ}$ and $\sim 58^{\circ} 2 \theta$ when the system was equilibrated for 2 weeks at $75^{\circ} \mathrm{C}$ and $\mathrm{pH} 3.0$.

XPS was used to confirm the surface structure for fresh and As(V)-loaded CMC-HFO composites. The wide scan XPS spectrum of the CMC-HFO composites (Fig. 6a) shows the photoelectron lines at binding energies of about 284.0, 530.0, 710.0, and 46.2 eV are attributed to C1s, O1s, Fe2p, and As3d respectively. Two photoelectron peaks located at 711.3 and $724.5 \mathrm{eV}$ are found in the Fe $2 \mathrm{p}$ spectrum (Fig. $6 \mathrm{~b}$ ), which can be assigned to the Fe2 $\mathrm{p}_{3 / 2}$ and $\mathrm{Fe} 2 \mathrm{p}_{1 / 2}$ of $\mathrm{FeOOH}$, respectively. The O1s spectrum (Fig. 6c) can be deconvoluted into two peaks at 530.7and 532.7, which are attributed to the binding energies of $\mathrm{Fe}-\mathrm{O}$, and $\mathrm{C}-\mathrm{O}^{41}$. The high resolution XPS As $3 \mathrm{~d}$ spectrum after $\mathrm{As}(\mathrm{V})$ adsorption showed a remarkable increase in peak size located at $46.2 \mathrm{eV}$ (Fig. 6d), and signified the successful $\mathrm{As}(\mathrm{V})$ binding to $\mathrm{CMC}-\mathrm{HFO}$ nanoparticles. Moreover, the $\mathrm{O} 1 \mathrm{~s}$ spectrum (Fig. 6c) is deconvoluted into four components of $\mathrm{Fe}-\mathrm{O}, \mathrm{As}-\mathrm{O}, \mathrm{C}-\mathrm{O}$ and $-\mathrm{OH}$. The appearance of As-O peaks at $529.9 \mathrm{eV}$ indicates the adsorption of arsenic onto the surface of the adsorbents. A significant peak at $534.3 \mathrm{eV}$ appears loaded with $\mathrm{As}(\mathrm{V})$ on CMC-HFO composites ${ }^{43}$, implying the alteration of oxygen constituents of CMC-HFO after As(V) sorption (Fig. 6c). A significant increase of the Fe2p spectra intensity of CMC-HFO and a spectra shift $(711.3 \mathrm{eV})$ were observed following $\mathrm{As}(\mathrm{V})$ sorption, showing strong interactions between $\mathrm{As}(\mathrm{V})$ and Fe atoms. Thus Fe atoms likely played an important role in $\mathrm{As}(\mathrm{V})$ sorption.

TEM spectra of As-laden CMC-HFO nanoparticles after reaction (Fig. 1) showed that the agglomeration as well as size of the nanoparticles increased probably due to the formation of the adsorption/co-precipitation of $\mathrm{As}(\mathrm{V})$ on CMC-HFO particles surface ${ }^{53}$. This result is consistent with the results of XRD, XPS, FTIR and dual-mode isotherm model. 

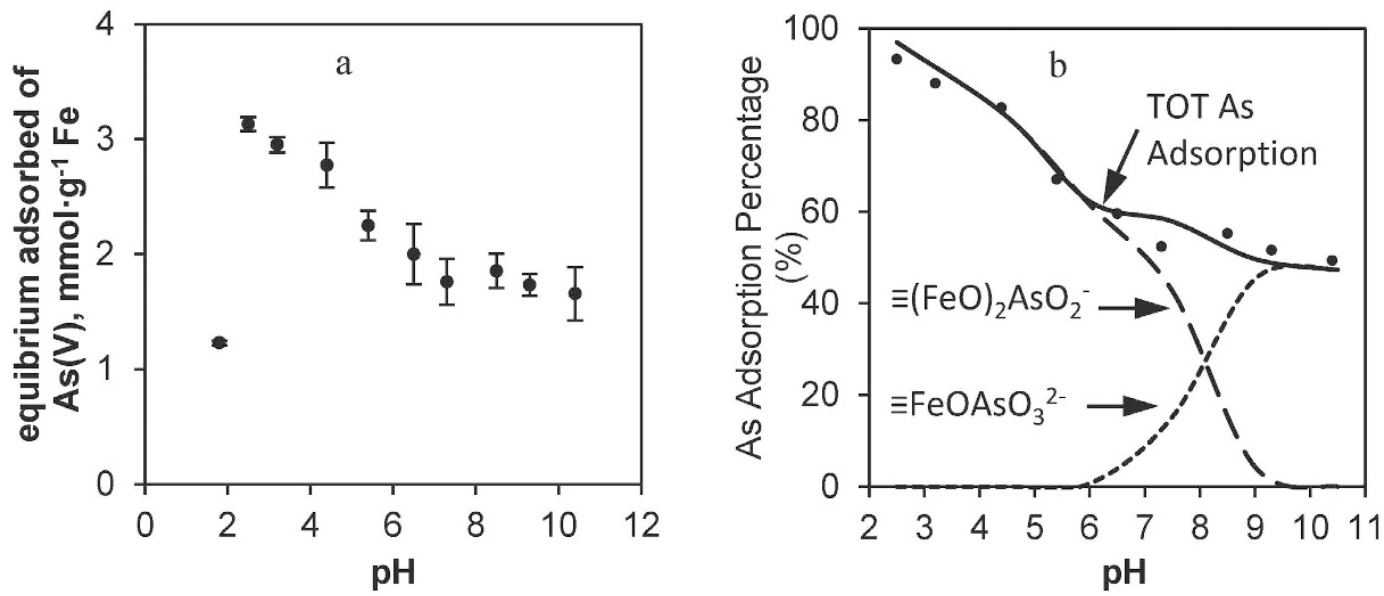

Figure 7. (a) Arsenic removal as a function of $\mathrm{pH}$. (b) speciation of adsorbed arsenate at total As $=10 \mathrm{mg} \cdot \mathrm{L}^{-1}$ using SCM model. HFO nanoparticles $=100 \mathrm{mg} \cdot \mathrm{L}^{-1}$ as Fe. Data are shown as symbols and model simulations are shown as lines.

Effects of $\mathrm{pH}$ on arsenic removal. The formation of HFO particles via surface complexation and surface precipitation are $\mathrm{pH}$-dependent processes. Solution $\mathrm{pH}$ can affect both arsenate speciation and surface charge of $\mathrm{CMC}-\mathrm{HFO}$ nanoparticles and further change the sorption capacity $\mathrm{As}(\mathrm{V})$. Figure 7 shows the effects of equilibrium $\mathrm{pH}$ on $\mathrm{As}(\mathrm{V})$ removal by $\mathrm{CMC}-\mathrm{HFO}$. As $(\mathrm{V})$ uptake decreased from 3.1 to $1.9 \mathrm{mmol} \cdot \mathrm{g}^{-1} \mathrm{Fe}$ as $\mathrm{pH}$ increased from 2.5 to 6.5 and then remained at $\sim 1.8 \mathrm{mmol} \cdot \mathrm{g}^{-1} \mathrm{Fe}$ at $\mathrm{pH} 6.5-10.4$. Increasing $\mathrm{pH}$ has been reported to decrease $\mathrm{As}(\mathrm{V})$ adsorption on ferric hydroxide ${ }^{16,32,41,54}$. The surface charge of nanoparticles remained negative at $\mathrm{pH}$ values as low as 2.5 ( $\zeta$ potential $-0.65 \mathrm{mV}$ ) as shown in Figure S5. It could be inferred that the $\mathrm{pH}_{\mathrm{PZC}}$ of stabilized HFO nanoparticles in our study was $<2.5$ and that at $\mathrm{pH}>\mathrm{pHpzc}$, the HFO surface was negatively charged. The higher the solution $\mathrm{pH}$, the more negatively charged the surface of the HFO nanoparticles is, and the less sorption of As(V) onto the HFO nanoparticles occurs. As shown in Figure S6, at $\mathrm{pH}<6.5$, the HFO particles increasingly dissolved, and the concentration of Fe ions, which react with As (V) in solution, increased (Figure S6). In addition, the concentrations of As species are $\mathrm{pH}$-dependent: the acid dissociation constants $\left(\mathrm{pK}_{\mathrm{a} 1}, \mathrm{pK}_{\mathrm{a} 2}\right.$, and $\mathrm{pK}_{\mathrm{a} 3}$ ) for arsenate are $2.2,6.9$, and 12 , respectively ${ }^{10}$. As a result, an excess of $\mathrm{OH}^{-}$accumulates at the HFO particle-solution interface, promoting the conversion of $\mathrm{H}_{2} \mathrm{AsO}_{4}{ }^{-}$from the bulk solution to $\mathrm{HAsO}_{4}{ }^{2-}$ at the $\mathrm{HFO}$ nanoparticle surface. At $\mathrm{pH}>7.3$, although the more adsorbable $\mathrm{HAsO}_{4}{ }^{2-}$ ions predominate, the competition from $\mathrm{OH}^{-}$ions becomes increasingly fierce, resulting in reduced As uptake with increasing $\mathrm{pH}$.

However, when $\mathrm{pH}$ decreased to 1.8 , adsorbed $\mathrm{As}(\mathrm{V})$ sharply decreased to $1.2 \mathrm{mmol} \cdot \mathrm{g}^{-1} \mathrm{Fe}$. It was attributed to the dominant As species $\mathrm{H}_{3} \mathrm{AsO}_{4}$ at $\mathrm{pH}<2.2$, which hindered the adsorption of $\mathrm{As}(\mathrm{V})$ on the particles ${ }^{54}$. It can be concluded that an effective removal of monovalent $\mathrm{As}(\mathrm{V})$ can be accompanied by using CMC-HFO nanoparticles, which is consistent with the reports from Ghimire et al. ${ }^{54}$. The optimum adsorption conditions for arsenate are $\mathrm{pH}=2.5$ and the maximum removal percentage was around $93.3 \%$.

A surface complexation model (SCM) with the double-layer model (2-pk DLM) was used to describe the arsenic sorption edges. Similar surface complexes have been used in previous studies ${ }^{16,55,56}$. The surface sites $(\equiv \mathrm{FeOH})$ were considered similar to those of two-line ferrihydrite ${ }^{55}$. Constants for protonation of the surface hydroxyl groups and aqueous species were taken from previous studies shown in Table 2. To simplify the model, only nonprotonated bidentate surface complexes were considered ${ }^{55}$. The intrinsic As $(\mathrm{V})$ surface complexation constants for $\mathrm{As}(\mathrm{V})$ adsorption optimized with DLM are shown in Table 2 using Minteq software.

The SCM fits the experimental data for As(V) adsorption percent over the range of pH 2.5-10.4 (Fig. 7b). Better agreement between the model and the experimental data are obtained in a $\mathrm{pH}$ gradient. The percentage distributions of arsenate species are $\sim 50.0 \%$ for $\mathrm{H}_{2} \mathrm{AsO}_{4}{ }^{-}$and $\sim 9.0 \%$ for $\mathrm{HAsO}_{4}{ }^{2-}$ in As3d spectra at $\mathrm{pH}$ 7.0. The peaks corresponding to these species are centered at 47.2 and $45.5 \mathrm{eV}$ respectively in XPS spectra ${ }^{53}$. The SCM model results suggested that the intrinsic binuclear, bidentate surface complex $\equiv(\mathrm{FeO})_{2} \mathrm{AsO}_{2}{ }^{-}$was predicted to be the dominant form of adsorbed arsenate over $\mathrm{pH}$ 2.5-5.9 and the monodentate complex $\equiv \mathrm{FeOAsO}_{3}{ }^{2-}$ was predicted to dominate above $\mathrm{pH} 6.8$ (Fig. $7 \mathrm{~b}$ ). The results were consistent with those previously reported. Zeng et al. ${ }^{55}$ concluded that the predominant, adsorbed arsenate and phosphate species on iron oxide-based sorbent were modeled as bidentate, binuclear surface complexes at low $\mathrm{pH}$ and as monodentate complexes at high $\mathrm{pH}$.

After $270 \mathrm{~d}$ of aging at room temperature, sorption capacity changed from 3.13 to 2.08 , from 1.99 to 1.63 , and from 1.66 to $1.70 \mathrm{mmol} / \mathrm{g}$ for $\mathrm{pH} 2.5,7.1$, and 11.0 , respectively. Only small changes in sorption capacity were associated with the $\mathrm{pH}$ changes. The $\mathrm{pH}$ values revert towards neutrality after aging: the $\mathrm{pH}$ values of the solutions that start at $\mathrm{pH} 2.5$ and 11 change to 3.3 and 10.2, respectively, after $270 \mathrm{~d}$.

Regeneration. The HFO nanoparticles after the adsorption test can be regenerated by stirring with $0.1 \mathrm{~mol} \cdot \mathrm{L}^{-1} \mathrm{NaOH}$ solution at $25^{\circ} \mathrm{C}$ for $4 \mathrm{~h}$ respectively ${ }^{26,41,43}$. Meanwhile the recyclability of CMC-HFO for As $(\mathrm{V})$ adsorption was investigated by repeating the adsorption/desorption process three times, the results of which are presented in Figure S7. The adsorption efficiency of CMC-HFO for As(V) showed no significant loss after three 


\begin{tabular}{|c|c|}
\hline \multicolumn{2}{|l|}{ material properties and experimental Conditions } \\
\hline specific surface area $\left(\mathrm{m}^{2} \cdot \mathrm{g}^{-1}\right)$ & $600^{\mathrm{a}}$ \\
\hline solid concentration $\left(\mathrm{g} \cdot \mathrm{L}^{-1}\right)$ & 0.1 \\
\hline equilibration time (h) & 72 \\
\hline \multirow[t]{2}{*}{ site concentration (mM) } & 1.5 \\
\hline & 1.1 \\
\hline sorption density (mol As per mol Fe) & $0.26^{\mathrm{b}}$ \\
\hline \multicolumn{2}{|l|}{ intrinsic surface complexation constants } \\
\hline reaction & $\log \mathrm{K}$ \\
\hline \multicolumn{2}{|l|}{ surface acidity reaction } \\
\hline$\equiv \mathrm{FeOH}+\mathrm{H}^{+}=\equiv \mathrm{FeOH}_{2}^{+}$ & $-6.51^{c}$ \\
\hline$\equiv \mathrm{FeOH}=\equiv \mathrm{FeO}^{-}+\mathrm{H}^{+}$ & $-8.93^{c}$ \\
\hline \multicolumn{2}{|l|}{ Arsenate adsorption constants } \\
\hline$\equiv \mathrm{FeOH}+\mathrm{AsO}_{4}^{3-}+\mathrm{H}^{+}=\equiv \mathrm{FeOAsO}_{3}^{2-}+\mathrm{H}_{2} \mathrm{O}$ & $18.9^{\mathrm{d}}$ \\
\hline$\equiv(\mathrm{FeOH})_{2}+\mathrm{AsO}_{4}^{3-}+2 \mathrm{H}^{+}=\equiv(\mathrm{FeO})_{2} \mathrm{AsO}_{2}^{-}+2 \mathrm{H}_{2} \mathrm{O}$ & $27.1^{\mathrm{d}}$ \\
\hline
\end{tabular}

Table 2. Material properties, experimental conditions, reactions and parameters used in surface complexation modeling for adsorption of arsenate on HFO nanoparticles. ${ }^{\mathrm{a} A s s u m e d ~ v a l u e}{ }^{56}$; ${ }^{\mathrm{b}} \mathrm{Obtained}$ from sorption isotherm; ${ }^{\mathrm{C}}$ Reference ${ }^{16}$; ${ }^{\mathrm{T}}$ This study.

successive cycles (99.7-94.9\%). The reusability of CMC-HFO demonstrates its advantage for As(V) removal from drinking water. The deterioration in capacity for the second and third cycle is $2.0 \%$ and $5 \%$ for As $(\mathrm{V})$, respectively. These results showed that CMC-HFO has sufficient chemical stability over several sorption-desorption repetitions.

To further confirm the effectiveness of HFO nanoparticles in arsenic removal from bodies of water, the adsorption experiments were performed in wastewater samples from Realgar mine tailings with an initial arsenic concentration of $38.2 \mathrm{mg} \cdot \mathrm{L}^{-1}$, since the composition of real wastewater is more complex. Although large amounts of other species exist in the wastewater (detailed information is shown in Table S1, SI), modified HFO nanoparticles still show an excellent performance with an adsorption efficiency of $\sim 90.5 \%$ for $\mathrm{As}(\mathrm{V})$ (Figure S8). For continuous treatment by CMC-HFO for three times, the concentration can be decreased to $5.6 \mu \mathrm{g} \cdot \mathrm{L}^{-1}$, far below the standard of $10 \mu \mathrm{g} \cdot \mathrm{L}^{-1}$ suggested by WHO. These results further confirm applicability of CMC-HFO nanoparticles in arsenic removal from wastewater without pre-treatment.

\section{Conclusions}

This study addressed the potential for and viability issues of the nanoparticles for As(V) removal from water. The particle stabilization technique not only facilitated deliverability, but increased the As(V) sorption capacity by up to 1.69 times with $0.064 \mathrm{wt} \% \mathrm{CMC}$. However, excessive CMC can inhibit As(V)'s sorbed to particle surface sites both kinetically and thermodynamically. The rate-limiting step of As(V) removal rates for CMC-HFO nanoparticles is sorption rather than diffusion. At initial $\mathrm{As} / \mathrm{Fe}<0.4$, more than $97 \%$ removal was attributed to adsorption, but as $\mathrm{As}(\mathrm{V})$ loading increased, the adsorption capacity of the HFO nanoparticles became saturated, leading to chemical precipitation: at initial As/Fe $>0.6$, precipitation caused $15-28 \%$ of $\mathrm{As}(\mathrm{V})$ removal. Furthermore, the FTIR, XRD and XPS analysis also supports that CMC-HFO takes up As(V) through concurrent precipitation (formation of crystalline ferric arsenate) and adsorption. Media $\mathrm{pH}$ was an important factor controlling the arsenate species present at the CMC-HFO nanoparticle surface. This study also demonstrated that the particles can be applied in a device to continuously treat arsenic-polluted water from a realgar mine, lowering concentrations from $38.2 \mathrm{mg} \cdot \mathrm{L}^{-1}$ to $5.6 \mu \mathrm{g} \cdot \mathrm{L}^{-1}$ below the WHO standard. The CMC- modified HFO nanoparticles may designed to be deliverable into contaminated soil or sediment to facilitate in situ immobilization of As(V).

\section{Methods}

Materials. Hydrous ferric oxide (HFO) nanoparticles were modified by CMC or starch via a water-based approach ${ }^{57}$. The modification was conducted in a $1 \mathrm{~L}$ flask in the presence of $1 \mathrm{wt} \%$ starch or CMC stock solution, which was prepared at room temperature following the method from $\mathrm{He}$ et al. ${ }^{39}$. The detailed method is described in S2 in SI. The final suspension of HFO nanoparticles was dialyzed as rapidly as possible to remove electrolytes until an electric conductivity (EC) value was below $10 \mu \mathrm{s} / \mathrm{cm}$.

Physical characterization of modified HFO nanoparticles. The modified HFO nanoparticles were characterized using transmission electron microscopy (TEM, JEM-2010 JEOL Ltd., Tokyo, Japan), X-ray diffraction (XRD, Bruker AXS, Inc., Madison, WI, USA), X-ray photoelectron spectroscopy (XPS, Thermo escalab 250Xi, USA) and Fourier transform infrared (FTIR) spectroscopy. Dynamic light scattering (DLS) analysis the dynamic particle size distribution and $\zeta$ potential of HFO particles employed a Malvern Zetasizer Nano ZS (Malvern Instruments, Worcestershire, UK). Section S3 of SI provides details of the methods.

Effects of the modifier type and concentration on HFO nanoparticle stability and As sorption. To study the modifier's effects, HFO particles were prepared at a fixed HFO concentration of $100 \mathrm{mg} \cdot \mathrm{L}^{-1}$ as Fe and modified with different concentrations of CMC or starch (0-0.161 wt \% and $0-0.4 \mathrm{wt} \%$, respectively). To qualify 
the nanoparticles' physical stability/settleability after $2 \mathrm{~d}$ aging, the supernatant samples' visual transparency was then compared using UV-vis absorbance (UV-2550PC, Shimadzu Corporation, Japan). Meanwhile, the supernatant samples were digested with $12 \mathrm{M} \mathrm{HCl}$ for $5 \mathrm{~min}$, which completely dissolved the nanoparticles, and then analyzed for total Fe.

Arsenic sorption tests. Batch kinetics experiments were conducted in $50 \mathrm{~mL}$ centrifuge tubes. As $(\mathrm{V})$ stock solution was prepared by dissolving sodium arsenate dodecahydrate $\left(\mathrm{Na}_{3} \mathrm{AsO}_{4} \cdot 12 \mathrm{H}_{2} \mathrm{O}\right)$ into Milli-Q water. Each reactor contained $8 \mathrm{~mL}$ of CMC-stabilized or non-stabilized HFO suspension $\left(500 \mathrm{mg} \cdot \mathrm{L}^{-1}\right)$, which was then diluted by adding $32 \mathrm{~mL}$ of a solution, yielding a final solution containing $100 \mathrm{mg} \cdot \mathrm{L}^{-1}$ of HFO. Sorption of As(V) was initiated by injecting an stock solution into the reactors, resulting in an initial $\mathrm{As}(\mathrm{V})$ concentration of 10 and $30 \mathrm{mg} \cdot \mathrm{L}^{-1}$. The $\mathrm{pH}$ of the mixture was kept to 7.0 with $0.1 \mathrm{M} \mathrm{HNO}_{3}$ and $0.1 \mathrm{M} \mathrm{NaOH}$. The mixtures were continuously shaken on a thermostatic shaker at $170 \mathrm{rpm}$ and at $25 \pm 1{ }^{\circ} \mathrm{C}$. At predetermined times, duplicate vials were sacrificially sampled. The samples were then filtered through a $25 \mathrm{~nm}$ membrane filters (VSWP, Millipore, USA) and then analyzed for arsenic concentration in the filtrates. The filtration was able to retain $>96 \%$ of the nanoparticles as determined by analyzing total iron in the filtrate, without retaining any soluble As. The final $\mathrm{pH}$, measured at the end of the experiments, is reported. The same test procedure of equilibrium sorption test was followed except the varying initial $\mathrm{As}(\mathrm{V})$ concentration $0.1-100 \mathrm{mg} \cdot \mathrm{L}^{-1}$. To study the $\mathrm{pH}$ effect, the sorption tests were carried out at $\mathrm{pH}$ from 1.8-10.4. Control sorption experiments with DI water, CMC or starch but without particles were performed. The results showed that there was nearly no loss of arsenate in solution during the $72 \mathrm{~h}$ tests at $\mathrm{pH}$ in the study (Figure S9 of SI). Experiments were repeated three times, and all of the data are the average of the three.

Analytical methods. Arsenic concentration in the solution was analyzed using a hydride generation atomic fluorescence spectrometer (HG-AFS9120, Titan Instruments, Beijing, China). The detection limits for As were $0.02-0.04 \mathrm{mg} \cdot \mathrm{L}^{-1}$. Iron concentration in solution was analyzed using a inductively coupled plasma mass spectrometer (ICP, Optima 5300DV, USA)

\section{References}

1. Jang, M., Chen, W. \& Cannon, F. S. Preloading Hydrous Ferric Oxide Into Granular Activated Carbon for Arsenic Removal. Environ. Sci. Technol. 42, 3369-3374 (2008).

2. Kanel, S. R., Greneche, J. \& Choi, H. Arsenic (V) Removal From Groundwater Using Nano Scale Zero-Valent Iron as a Colloidal Reactive Barrier Material. Environ. Sci. Technol. 40, 2045-2050 (2006).

3. Giménez, J., Martínez, M., de Pablo, J., Rovira, M. \& Duro, L. Arsenic Sorption Onto Natural Hematite, Magnetite, and Goethite. J. Hazard. Mater. 141, 575-580 (2007).

4. Tang, W., Li, Q., Gao, S. \& Shang, J. K. Arsenic (III, V) Removal From Aqueous Solution by Ultrafine $\alpha-\mathrm{Fe}_{2} \mathrm{O}_{3} \mathrm{Nanoparticles}$ Synthesized From Solvent Thermal Method. J. Hazard. Mater. 192, 131-138 (2011).

5. Silva, J. et al. The Role of Al-Goethites On Arsenate Mobility. Water Res. 44, 5684-5692 (2010).

6. Tokoro, C., Yatsugi, Y., Koga, H. \& Owada, S. Sorption Mechanisms of Arsenate During Coprecipitation with Ferrihydrite in Aqueous Solution. Environ. Sci. Technol. 44, 638-643 (2009).

7. Wang, S., Gao, B., Li, Y., Creamer, A. E. \& He, F. Adsorptive Removal of Arsenate From Aqueous Solutions by Biochar Supported Zero-Valent Iron Nanocomposite: Batch and Continuous Flow Tests. J. Hazard. Mater. (2016).

8. Li, W. et al. Differential Pair Distribution Function Study of the Structure of Arsenate Adsorbed On Nanocrystalline $\Gamma$-Alumina. Environ. Sci. Technol. 45, 9687-9692 (2011).

9. Opiso, E., Sato, T. \& Yoneda, T. Adsorption and Co-Precipitation Behavior of Arsenate, Chromate, Selenate and Boric Acid with Synthetic Allophane-Like Materials. J. Hazard. Mater. 170, 79-86 (2009).

10. An, B., Steinwinder, T. R. \& Zhao, D. Selective Removal of Arsenate From Drinking Water Using a Polymeric Ligand Exchanger. Water Res. 39, 4993-5004 (2005).

11. Genç-Fuhrman, H., Tjell, J. C. \& McConchie, D. Increasing the Arsenate Adsorption Capacity of Neutralized Red Mud (Bauxsol). J. Colloid Interf. Sci. 271, 313-320 (2004).

12. Chen, W., Parette, R., Zou, J., Cannon, F. S. \& Dempsey, B. A. Arsenic Removal by Iron-Modified Activated Carbon. Water Res. 41, 1851-1858 (2007).

13. Reed, B. E., Vaughan, R. \& Jiang, L. As (III), as (V), Hg, and Pb Removal by Fe-oxide Impregnated Activated Carbon. J. Environ. Eng. 126, 869-873 (2000).

14. Farquhar, M. L., Charnock, J. M., Livens, F. R. \& Vaughan, D. J. Mechanisms of Arsenic Uptake From Aqueous Solution by Interaction with Goethite, Lepidocrocite, Mackinawite, and Pyrite: An X-ray Absorption Spectroscopy Study. Environ. Sci. Technol. 36, 1757-1762 (2002)

15. Manning, B. A., Fendorf, S. E. \& Goldberg, S. Surface Structures and Stability of Arsenic (III) On Goethite: Spectroscopic Evidence for Inner-Sphere Complexes. Environ. Sci. Technol. 32, 2383-2388 (1998).

16. Dixit, S. \& Hering, J. G. Comparison of Arsenic (V) and Arsenic (III) Sorption Onto Iron Oxide Minerals: Implications for Arsenic Mobility. Environ. Sci. Technol. 37, 4182-4189 (2003).

17. Gupta, A., Yunus, M. \& Sankararamakrishnan, N. Zerovalent Iron Encapsulated Chitosan Nanospheres-a Novel Adsorbent for the Removal of Total Inorganic Arsenic From Aqueous Systems. Chemosphere. 86, 150-155 (2012).

18. Gong, Y., Liu, Y., Xiong, Z., Kaback, D. \& Zhao, D. Immobilization of Mercury in Field Soil and Sediment Using Carboxymethyl Cellulose Stabilized Iron Sulfide Nanoparticles. Nanotechnology. 23, 294007-294020 (2012).

19. He, F., Zhao, D., Liu, J. \& Roberts, C. B. Stabilization of Fe-Pd Nanoparticles with Sodium Carboxymethyl Cellulose for Enhanced Transport and Dechlorination of Trichloroethylene in Soil and Groundwater. Ind. Eng. Chem. Res. 46, 29-34 (2007).

20. Su, C. \& Puls, R. W. In Situ Remediation of Arsenic in Simulated Groundwater Using Zerovalent Iron: Laboratory Column Tests On Combined Effects of Phosphate and Silicate. Environ. Sci. Technol. 37, 2582-2587 (2003).

21. He, F. \& Zhao, D. Manipulating the Size and Dispersibility of Zerovalent Iron Nanoparticles by Use of Carboxymethyl Cellulose Stabilizers. Environ. Sci. Technol. 41, 6216-6221 (2007).

22. Zhang, M., Pan, G., Zhao, D. \& He, G. XAFS Study of Starch-Stabilized Magnetite Nanoparticles and Surface Speciation of Arsenate. Environ. Pollut. 159, 3509-3514 (2011).

23. Feng, L., Cao, M., Ma, X., Zhu, Y. \& Hu, C. Superparamagnetic High-Surface-Area Fe 3 O 4 Nanoparticles as Adsorbents for Arsenic Removal. J. Hazard. Mater. 217, 439-446 (2012). 
24. Olyaie, E., Banejad, H., Afkhami, A., Rahmani, A. \& Khodaveisi, J. Development of a Cost-Effective Technique to Remove the Arsenic Contamination From Aqueous Solutions by Calcium Peroxide Nanoparticles. Sep. Purif. Technol. 95, 10-15 (2012).

25. Bhaumik, M., Maity, A., Srinivasu, V. V. \& Onyango, M. S. Enhanced Removal of Cr (VI) From Aqueous Solution Using polypyrrole/ $\mathrm{Fe}_{3} \mathrm{O}_{4}$ Magnetic Nanocomposite. J. Hazard. Mater. 190, 381-390 (2011).

26. Badruddoza, A. Z. M. et al. Ionically Modified Magnetic Nanomaterials for Arsenic and Chromium Removal From Water. Chem. Eng. J. 225, 607-615 (2013).

27. Gollavelli, G., Chang, C. \& Ling, Y. Facile Synthesis of Smart Magnetic Graphene for Safe Drinking Water: Heavy Metal Removal and Disinfection Control. ACS Sustain. Chem. Eng. 1, 462-472 (2013).

28. Xiong, Z., He, F., Zhao, D. \& Barnett, M. O. Immobilization of Mercury in Sediment Using Stabilized Iron Sulfide Nanoparticles. Water Res. 43, 5171-5179 (2009).

29. He, F. \& Zhao, D. Preparation and Characterization of a New Class of Starch-Stabilized Bimetallic Nanoparticles for Degradation of Chlorinated Hydrocarbons in Water. Environ. Sci. Technol. 39, 3314-3320 (2005).

30. Gong, Y., Liu, Y., Xiong, Z. \& Zhao, D. Immobilization of Mercury by Carboxymethyl Cellulose Stabilized Iron Sulfide Nanoparticles: Reaction Mechanisms and Effects of Stabilizer and Water Chemistry. Environ. Sci. Technol. 48, 3986-3994 (2014).

31. Liang, Q., Zhao, D., Qian, T., Freeland, K. \& Feng, Y. Effects of Stabilizers and Water Chemistry On Arsenate Sorption by Polysaccharide-Stabilized Magnetite Nanoparticles. Ind. Eng. Chem. Res. 51, 2407-2418 (2012).

32. Zhang, K., Dwivedi, V., Chi, C. \& Wu, J. Graphene Oxide/Ferric Hydroxide Composites for Efficient Arsenate Removal From Drinking Water. J. Hazard. Mater. 182, 162-168 (2010).

33. Raven, K. P., Jain, A. \& Loeppert, R. H. Arsenite and Arsenate Adsorption On Ferrihydrite: Kinetics, Equilibrium, and Adsorption Envelopes. Environ. Sci. Technol. 32, 344-349 (1998).

34. Yean, S. et al. Effect of Magnetite Particle Size On Adsorption and Desorption of Arsenite and Arsenate. J. Mater. Res. 20, 3255-3264 (2005).

35. Auffan, M. et al. Enhanced Adsorption of Arsenic Onto Maghemites Nanoparticles: As (III) as a Probe of the Surface Structure and Heterogeneity. Langmuir. 24, 3215-3222 (2008).

36. Arai, Y., Elzinga, E. J. \& Sparks, D. L. X-Ray Absorption Spectroscopic Investigation of Arsenite and Arsenate Adsorption at the Aluminum Oxide-Water Interface. Journal of Colloid \& Interface Science. 235, 80-88 (2001).

37. Juncheng Liu, He, F., Ed Durham, Dongye Zhao, A. \& Christopher, B. R. Polysugar-Stabilized Pd Nanoparticles Exhibiting High Catalytic Activities for Hydrodechlorination of Environmentally Deleterious Trichloroethylene. Langmuir. 24, 328-336 (2008).

38. Jiemvarangkul, P., Zhang, W. X. \& Lien, H. L. Enhanced Transport of Polyelectrolyte Stabilized Nanoscale Zero-Valent Iron (nZVI) in Porous Media. Chem. Eng. J. 170, 482-491 (2011).

39. He, F., Liu, J., Roberts, C. B. \& Zhao, D. One-Step "Green" Synthesis of Pd Nanoparticles of Controlled Size and their Catalytic Activity for Trichloroethene Hydrodechlorination. Ind. Eng. Chem. Res. 48, 6550-6557 (2009).

40. Zhu, J., Pigna, M., Cozzolino, V., Caporale, A. G. \& Violante, A. Sorption of Arsenite and Arsenate On Ferrihydrite: Effect of Organic and Inorganic Ligands. J. Hazard. Mater. 189, 564-571 (2011).

41. Goh, K. H., Lim, T. T. \& Dong, Z. Enhanced Arsenic Removal by Hydrothermally Treated Nanocrystalline Mg/Al Layered Double Hydroxide with Nitrate Intercalation. Environ. Sci. Technol. 43, 2537-2543 (2009).

42. An, B., Liang, Q. \& Zhao, D. Removal of Arsenic (V) From Spent Ion Exchange Brine Using a New Class of Starch-Bridged Magnetite Nanoparticles. Water Res. 45, 1961-1972 (2011).

43. Yang, J. et al. High-Content, Well-Dispersed $\gamma-\mathrm{Fe}_{2} \mathrm{O}_{3}$ Nanoparticles Encapsulated in Macroporous Silica with Superior Arsenic Removal Performance. Adv. Funct. Mater. 24, 1354-1363 (2014).

44. Mishra, A. K. \& Ramaprabhu, S. Functionalized Graphene Sheets for Arsenic Removal and Desalination of Sea Water. Desalination. 282,39-45 (2011).

45. Chen, M. L., Sun, Y., Huo, C. B., Liu, C. \& Wang, J. H. Akaganeite Decorated Graphene Oxide Composite for Arsenic Adsorption/ Removal and its Proconcentration at Ultra-Trace Level. Chemosphere. 130, 52-58 (2015).

46. Mishra, A. K. \& Ramaprabhu, S. Ultrahigh Arsenic Sorption Using Iron Oxide-Graphene Nanocomposite Supercapacitor Assembly. J. Appl. Phys. 112, 104315 (2012).

47. Matsunaga, H., Yokoyama, T., Eldridge, R. J. \& Bolto, B. A. Adsorption Characteristics of arsenic(III) and arsenic(V) On iron(III)loaded Chelating Resin Having lysine-N A. N A -Diacetic Acid Moiety. React. Funct. Polym. 29, 167-174 (1996).

48. Maity, D. \& Agrawal, D. C. Synthesis of Iron Oxide Nanoparticles Under Oxidizing Environment and their Stabilization in Aqueous and Non-Aqueous Media. J. Magn. Magn. Mater. 308, 46-55 (2007).

49. Ayob, A. et al. Kinetic Removal of $\mathrm{Cr}^{6+}$ by Carboxymethyl Cellulose-Stabilized Nano Zerovalent Iron Particles. Macedonian Journal of Chemistry \& Chemical Engineering. 34, 295-308 (2015).

50. Jia, Y., Xu, L., Wang, X. \& Demopoulos, G. P. Infrared Spectroscopic and X-ray Diffraction Characterization of the Nature of Adsorbed Arsenate On Ferrihydrite. Geochim. Cosmochim. Ac. 71, 1643-1654 (2007).

51. Goldberg, S. \& Johnston, C. T. Mechanisms of Arsenic Adsorption On Amorphous Oxides Evaluated Using Macroscopic Measurements, Vibrational Spectroscopy, and Surface Complexation Modeling. J. Colloid Interf. Sci. 234, 204-216 (2001).

52. Jia, Y., Xu, L., Fang, Z. \& Demopoulos, G. P. Observation of Surface Precipitation of Arsenate On Ferrihydrite. Environ. Sci. Technol. 40, 3248-3253 (2006)

53. Yu, X. et al. One-Step Synthesis of Magnetic Composites of Cellulose@Iron Oxide Nanoparticles for Arsenic Removal. J. Mater. Chem. A. 1, 959-965 (2012).

54. Ghimire, K. N. et al. Adsorptive Removal of Arsenic Using Orange Juice Residue. Sep. Sci. Technol. 37, 2785-2799 (2002).

55. Zeng, H., Fisher, B. \& Giammar, D. E. Individual and Competitive Adsorption of Arsenate and Phosphate to a High-Surface-Area Iron Oxide-Based Sorbent. Environ. Sci. Technol. 42, 147-152 (2008).

56. Dzombak, D. A. \& Morel, F. Surface Complexation Modeling: Hydrous Ferric Oxide. Surface Complexation Modeling Hydrous Ferric Oxide. 97-108 (1989).

57. Schwertmann, U. \& Cornell, R. M. Iron Oxides in the Laboratory. 105-110 John Wiley \& Sons, (New York, 2008).

\section{Acknowledgements}

This work was supported by the National Natural Science Foundation of China (41541007), Research Project Supported by Shanxi Scholarship Council of China (2014-061), and the Youth Science and Technology Research Fund of Shanxi Province (201601D202069). Thanks Hong Shan in the Analysis and Test Center of Institute of Environment and Sustainable Development in Agriculture, Chinese Academy of Agricultural Sciences for the help of As analysis.

\section{Author Contributions}

Z.-X.B. directed this research and was the overall in-charge. H.-L.J. and Z.-X.B. planned and designed the experiments. H.-L.J., Z.-X.B., and S.-S.M. analyzed and wrote the manuscript. H.-L.J., B.-L.Y., and W.-Y.N. performed the experiments and analyzed the data. All authors discussed the results and contributed in this manuscript. 


\section{Additional Information}

Supplementary information accompanies this paper at http://www.nature.com/srep

Competing financial interests: The authors declare no competing financial interests.

How to cite this article: Huo, L. et al. Enhanced removal of As (V) from aqueous solution using modified hydrous ferric oxide nanoparticles. Sci. Rep. 7, 40765; doi: 10.1038/srep40765 (2017).

Publisher's note: Springer Nature remains neutral with regard to jurisdictional claims in published maps and institutional affiliations.

(c) (i) This work is licensed under a Creative Commons Attribution 4.0 International License. The images or other third party material in this article are included in the article's Creative Commons license, unless indicated otherwise in the credit line; if the material is not included under the Creative Commons license, users will need to obtain permission from the license holder to reproduce the material. To view a copy of this license, visit http://creativecommons.org/licenses/by/4.0/

(C) The Author(s) 2017 